\title{
A Subcontratação Como Estratégia COMPETTTIVA NA CONSTRUÇÃo CIVIL
}

Ana Paula Silva dos Santos

Graduanda em Administração de Empresas pela Universidade Federal do Ceará ssanapaula@yahoo.com.br

João Adriano Ponciano Nobre

Eng. ${ }^{\circ}$ Civil, Mestre em Administração pela Universidade Federal do Ceará adrianonobre@bol.com.br

\section{Leonardo Leocádio Coelho de Souza \\ Economista, Mestre em Administracão pela Universidade Federal do Ceará leoleocadio@yahoo.com.br}

\author{
José de Paula Barros Neto \\ Eng. ${ }^{\circ}$ Civil, Dr. em Administração, \\ Prof. Adjunto da Universidade Federal Do Ceará \\ jpbarros@ufc.br
}

\section{RESUMO}

O presente artigo tem como objetivo investigar a subcontratação na construção civil através de um ponto de vista mais estratégico do que operacional. A preocupação com este assunto é justificada pelo crescimento do ato de subcontratar / terceirizar as atividades ou serviços. Este trabalho se inicia com a caracterização do macrocomplexo da Indústria da Construção Civil, que é fundamental para o desenvolvimento das idéias, seguido por uma discussão sobre a administração estratégica no ambiente da construção civil que embasa a discussão sobre subcontratação. Realizaram-se duas entrevistas com diretores de duas empresas construtoras de Fortaleza com a finalidade de verificar a visão do mercado com relação a este assunto. A partir desta discussão inicial, desenvolve-se a análise da subcontratação na construção civil, discutindo-se suas definições e razões, as relações de parcerias entre as empresas contratantes e as contratadas, bem como a avaliação da real necessidade dessas parcerias.

Palavras-chave: Subcontratação; Estratégia; Construção civil

\section{ABSTRACT}

The goal of this paper is to investigate the underbiring in the civil construction through a point of view which is more strategical than operational. The concern about this subject is justified by the growth of underbiring in companies activities and services. This study begins with the characterization of the macro complex of the civil construction industry, which is essential to the development of the ideas presented, followed by a discussion about strategic management in the context of civil construction, which supports the discussion about underhiring. Two construction companies managers in the city of Fortaleza, Ceará, were interviewed with the purpose of identifying the view of the market regarding this subject. Based on this, an analyses about civil construction's underbiring is developed, in which definitions, motivations and partnerships between the biring companies and the hired ones are discussed, as well as an assessment of the real needs for such partnerships is made.

Key-words: Underhiring; Strategical; Civil Construction 


\section{INTRODUÇÃO}

A importância sócio-econômica e estratégica para o desenvolvimento do país que todos os subsetores da Indústria da Construção Civil (ICC) possuem é inegável. De acordo com Mello (1997), baseado em dados do SENAI de 1995, esta importância é traduzida em uma participação considerável do PIB nacional e nos níveis de atividades da indústria de fornecedores ao longo de toda a cadeia produtiva. Além disso, a ICC constitui-se em um dos elementos-chave na geração de emprego e consumo e bens e serviços provenientes de outros setores de produção.

Como integrante da ICC encontra-se o subsetor de edificações, que se caracteriza por ser muito dependente das políticas macroeconômicas, sendo altamente vulnerável a flutuações econômicas. Devido ao baixo fôlego econômico-financeiro, a empresa de pequeno porte costuma sucumbir diante das pressões dos períodos recessivos prolongados (MELLO, 1997).

Nota-se que o setor da construção civil estava acostumado a uma economia em que o preço do produto final era resultante da soma dos custos de produção da empresa e do lucro previamente arbitrado. No atual momento o setor passa por uma nova formulação na qual o lucro passa a ser resultante do diferencial entre o preço praticado pelo mercado e os custos da empresa.

Neste novo ambiente, mesmo com um bom segmento de mercado regional é essencial a elaboração de análises estratégicas, pois a competitividade está se tornando cada vez mais acirrada. Mesmo que a Indústria da Construção Givil - Subsetor de Edificações (ICCSE), alvo deste estudo, seja uma indústria tipicamente tradicional, ela não está livre desta ameaça. Daí, uma das necessidades de se obter uma maior vantagem competitiva.

Partindo para uma visão de gerenciamento dos riscos de um empreendimento na construção civil, verifica-se que os principais responsáveis são o proprietário e o construtor. Entretanto, sabe-se que muitos dos riscos identificados são também transferidos para outros agentes participantes do empreendimento (terceirizados/subcontratados).

O objetivo deste trabalho encontra-se nesta perspectiva. É necessário investigar a questão da subcontratação na construção civil do ponto de vista estratégico, pois se visualiza uma tendência de crescimento no ato de subcontratar/ terceirizar atividades ou serviços.

Sendo assim, este trabalho tem como objetivo analisar a subcontratação na construção civil, a partir de uma abordagem estratégica, tratando das razões de se terceirizar uma atividade, analisando os critérios de seleção desses parceiros e discutindo a real necessidade de se terceirizar.

Para isso realizou-se uma pesquisa qualitativa com aplicação de uma entrevista semi-estruturada com os diretores de duas empresas do subsetor Edificações da cidade de Fortaleza. Posteriormente fez-se uma análise comparando-se a visão do mercado (resultado das entrevistas) com a literatura existente sobre o assunto.

\section{OMACROCOMPLEXO DA CONSTRUÇÃO CIVIL}

A Indústria da Construção Civil, a partir dos estudos atuais da economia industrial, passou a ser analisada não mais como uma atividade fim isolada, mas sim através de uma visão mais ampla, onde se analisa o Macrocomplexo da Construção Civil. Isto é conseqüência das relações muito estreitas que existem entre a Construção Civil e as várias cadeias produtivas precedentes e sucedentes, que fornecem os insumos necessários para a realização de um projeto concebido (SILVA apud PORTO, 1999).

Do ponto de vista da mão-de-obra a ICC tem como característica principal o baixo nível tecnológico e a pouca escolaridade, haja vista que o seu treinamento se realiza quase sempre durante a execução das obras, onde os trabalhadores mais qualificados agem como agentes de for mação dos menos qualificados. Além disso, a absorção deste contingente é potencializada em tempos de crise em outros setores. Outro fator a ser considerado é que o principal fornecedor de força de trabalho para a construção civil é o setor agrícola, sendo esta composta, preponderantemente, por imigrantes rurais (MEDEIROS apud SOARES, 1997).

Partindo para o subsetor de edificações dentro do macrocomplexo da construção civil, de acordo com Fisher (apud MELLO, 1997), pode-se ter a seguinte forma de segmentação deste subsetor: edificações industriais, edificações comerciais, restauração, habitação para o setor privado, habitação para o setor público, serviços de manutenção, serviços especializados.

Com a decadência do BNH (Banco Nacional da Habitação) e os entraves no acesso a outras fontes de financiamento, as empresas de pequeno porte tiveram que estudar novas formas de alavancagem financeira, optando, muitas delas, pelas obras por grupo fechado na qual os clientes financiam os empreendimentos da empresa. Pela mesma razão, uma parte considerável destas empresas passou a lançar mão de uma política de marketing mais agressivo (PORTO, 1999).

Sendo assim, a ICCSE (Indústria da Construção Civil Subsetor de Edificações), como toda a Indústria da Construção Civil, sofre influência direta com as flutuações sócio-política-econômicas do país, principalmente devido às características do seu produto. Construtoras e incorporadoras brotam e desaparecem com freqüência e poucas são as que conseguem atravessar uma década de vida (MELLO, 1997). 


\section{ADMINISTRAÇÃO ESTRATÉGICA NA CONSTRUÇÃO CIVIL}

No âmbito empresarial as decisões constituem o núcleo da responsabilidade administrativa. Cabe ao administrador decidir, o que implica selecionar entre as várias alternativas de cursos de ação aquela que lhe pareça mais adequada para o momento. Para tanto, utiliza-se dos avanços da tecnologia da informação, porém não despreza suas crenças e experiências anteriores, bem como sua visão de futuro. Aplica, simultaneamente, os métodos quantitativos para tornar a decisão o mais racional possível e sua própria percepção dos fatores ou condições que proporcionam a solução do problema, principalmente se este é do tipo nãoestruturado (SOLINO; EL-AOUAR apud SERRA, 2001).

Para o início da discussão sobre estratégia faz-se necessário adotar uma definição para estratégia. Sendo assim, adotou-se para este trabalho a visão de Andrews (apud BARROS NETO, 1999) que afirma que as estratégias são modelos de decisão em uma companhia que determinam e revelam seus objetivos e propósitos, produzem as principais políticas e planos para realizarem esses objetivos e definem o alcance dos negócios que a companhia persegue, o tipo de organização econômica e humana que ela pretende ser e a natureza das contribuições econômicas e não-econômicas que a empresa propicia para seus acionistas, empregados, clientes e a comunidade em geral.

De acordo com Farias Filho (apud PORTO, 1999), não existe nas micro, pequenas e médias empresas da ICCSE grandes preocupações em se fazer um planejamento estratégico de longo prazo consciente e explícito e nem fazer uso das teorias a respeito. Não há, na grande maioria destas empresas, uma política estratégica que viabilize a empresa a ter a produção perene durante a sua existência, ficando sujeitas às idas e vindas da conjuntura.

A visão de curto prazo domina o pensamento dos empresários da construção civil, sendo a assim a não visualização do processo estratégico (visão de longo prazo) na empresa pode gerar sua invalidação no mercado.

\subsection{As cinco forças de Porter na construção civil}

Analisando a ICCSE, utilizando-se da metodologia proposta por Porter (1986), bem como da experiência de aplicação do modelo na ICCSE e do estudo da estrutura de mercado realizado por diversos autores e de pesquisas realizadas em algumas empresas do setor, é possível fazer algumas considerações sobre as cinco forças que atuam no cenário estratégico empresarial:

- Ameaças de novos entrantes: a proliferação de empresas de pequeno porte é gerada pela existência de baixas barreiras de entrada na ICCSE. Isto é notório quando se visualiza que uma simples expansão de mercado vem acompanhada por uma invasão de micro empresas, já que as mesmas ingressam com um mínimo de investimento (PORTO, 1999).

- Ameaça de produtos substitutos: devido a não existência de produtos similares na indústria, praticamente não existem ameaças provindas de produtos substitutos ao produto final da ICCSE, embora haja grandes pressões quanto a tecnologias alternativas de materiais e processos empregados. De acordo com Barros Neto (1999), na ICCSE não há praticamente produtos substitutos quando se tem como enfoque a moradia e a tipologia do imóvel, pois as empresas são capazes de realizar o projeto que lhe for conveniente e permitido, dentro das condições técnicas e legislação vigente, apesar de elas se especializarem em determinados mercados. Entretanto, quando os imóveis são adquiridos para fins de investimento, os produtos do subsetor de edificações possuem inúmeros substitutos como por exemplo, mercado de ações, caderneta de poupança, entre outros (PORTO, 1999).

-Intensidade de rivalidade: em um mercado com concorrência quase perfeita, constituído majoritariamente de empresas de pequeno porte, como no subsetor de edificações, as poucas grandes empresas existentes são responsáveis pelo atendimento, já garantido, de uma fatia de mercado devido, principalmente, ao acesso aos planos de financiamento governamentais e a pressões políticas. No contexto das pequenas empresas, as estratégias adotadas não se diferem muito o que atenua um pouco a competitividade (PORTO, 1999).

- Poder de barganha dos clientes: reside no fato dos imóveis constituírem uma enorme parcela de suas economias, o que desencadeia uma proporcional seletividade. Visto isso, pode-se entender que as poucas diferenciações dos produtos existem mais nas formas de pagamentos e serviços agregados. Mas este poder vem aumentando gradativamente, à medida que o cliente toma consciência dos seus direitos, principalmente através do Código de Defesa do Consumidor, exigindo mais qualidade e serviços pósentrega (PALÁCIOS; VILLACRESES, 1994).

- Poder de barganha dos fornecedores: os fornecedores da ICCSE possuem auto poder de barganha, pois são organizados em torno de uma estrutura oligopolizada, principalmente nos insumos básicos com pouco ou nenhum produto substituto. Individualmente, entretanto, este poder de barganha é atenuado devido a homogeneidade do produto e do seu preço, e ao baixo custo de mudança. Nesta posição, pode-se afirmar também que os fornecedores são os grandes agentes de desenvolvimento de soluções tecnológicas (PORTO, 1999).

Considerando a importância do subempreiteiro neste subsetor e que este participa de um mercado concorrencial, pode-se também traçar a sua estratégia, analisando a influência das "forças competitivas de Porter". 
Sendo assim, de acordo com Obata e Serra (apud SERRA, 2001), o modelo de análise aplicado à empresa subempreiteira pode ser entendido em função:

- do número de competidores existentes: os subempreiteiros competem em um ambiente de grande rivalidade. As mudanças e novas exigências das construtoras fazem com que as empresas procurem trabalhar com firmas que, além de serem idôneas e qualificadas, procurem criar o sistema de parcerias;

- do poder de barganha dos fornecedores: passam se unir em cooperativas para aquisição de suprimentos e equipamentos, aumentando o seu poder de negociação;

- da ameaça de novas empresas: as barreiras existentes não dificultam a entrada de novas empresas, porém o seu posicionamento estratégico influenciará na aceitação e competitividade no mercado;

- do poder de barganha dos clientes-contratantes: pressão exercida pelos contratantes em busca de um melhor desempenho através da capacitação dos subempreiteiros, da formulação de contratos (responsabilidades, prazos, condições de fornecimento de materiais), da preocupação com a formação de parcerias.

Assim, em função do conhecimento do comportamento do seu mercado, as empresas deverão montar suas respectivas estratégias competitivas e se organizar administrativamente.

\subsection{A busca pela vantagem competitiva na ICC}

Para Porter (1985), o grau de competitividade de qualquer empresa depende de construir e manter uma vantagem competitiva. Considera também que a vantagem competitiva tem sua origem nas inúmeras atividades distintas que uma empresa pode executar no projeto, na produção, no marketing, na entrega e suporte do seu produto. Embora uma empresa possa ter inúmeros pontos fortes e fracos em relação a seus concorrentes existem dois tipos básicos de vantagem competitiva que a mesma pode possuir.

A primeira é a vantagem custos, que é obtida através do desenvolvimento de atividades econômicas e tecnológicas a custo menor que dos concorrentes para um mesmo conjunto de benefícios ofertados aos clientes. A segunda é a vantagem da diferenciação que é atingida pelo desenvolvimento de atividades econômicas e tecnológicas de tal forma que gere oferta de benefícios diferenciados, viabilizando um sobrepreço (PALÁCIOS; VILLACRESES, 1994).

Quando o escopo das estratégias referir-se a um segmento, tem-se uma posição de foco, podendo buscar vantagem sob a forma de custo ou diferenciação em um segmento específico de mercado e não para o mercado como um todo.

O processo de implantação de estratégias competitivas na ICCSE, ainda é muito raro no Brasil. Entretanto, Barros Neto (apud PORTO, 1999) faz algumas considerações que valem a pena serem apresentadas:
-A estratégia de liderança no custo total muitas vezes é conseguida. Entretanto isto acontece de forma distorcida, como por exemplo através da não conformidade de produtos em relação às normas técnicas, da sonegação fiscal, da ausência de serviços associados (assistência técnica e garantia da qualidade). Entretanto, existem algumas empresas que atingem a liderança no custo através de programas de qualidade e produtividade.

- A estratégia de liderança por diferenciação é muito pouco utilizada, se limitando apenas em alguns serviços diferenciados como atendimento personalizado, mas nada que seja resultado de investimentos em pesquisa e desenvolvimento e mesmo do conhecimento das necessidades dos clientes.

- A estratégia mais comum na ICCSE é a liderança por enfoque, pois as pequenas empresas se especializam em construir um padrão de imóvel para uma faixa de renda específica. As empresas também podem restringir a sua região de atuação para um bairro, cidade, etc.

Assim, uma empresa de construção de edifícios pode executar as diversas etapas do seu ciclo produtivo, com competência e de diversas formas. Porém, o mais importante é considerar que o processo é dinâmico, e que ele constantemente deve ser verificado a fim de atualizar as estratégias empresariais ao ambiente competitivo.

\section{ESTRATÉGIAS DE INTEGRAÇÃO VERTICAL}

A integração vertical é uma das estratégias que mais se destacam no ambiente competitivo de indústrias fragmentadas. A construção civil encaixa-se nesse modelo de ambiente fragmentado.

\begin{abstract}
São quatro os tipos de estratégias de integração vertical, sendo que cada estratégia genérica representa diferentes graus de aversão ao risco, desejos de controle e objetivos - fatia de mercado ("market share"), lucros de longo prazo, ou outras formas de liderança(HARRIGANapud VILLACRESES, 1994, p. 12).
\end{abstract}

Essas estratégias são nomeadas como: integração total, integração parcial, quase-integração e não-integração.

Segundo Serra (2001), a essência da estratégia de integração vertical consiste em definir se uma empresa irá "fazer ou comprar" (make or buy) seus insumos básicos, componentes ou serviços auxiliares. Porter (apud SERRA, 2001) complementa que a decisão de integrar verticalmente uma empresa deve extrapolar uma simples análise de custos e investimentos necessários. Ao decidir integrar, a questão principal da empresa passa a ser como se auto organizar para completar o seu trabalho (ECCLES apud SERRA, 2001).

As principais vantagens da integração vertical se apresentam como menores custos de transação, garantia de fornecimento e venda, facilidade de integração, maior retorno financeiro e maior barreira à entrada de novas empresas (BIANCHI apud SERRA, 2001). 
$\mathrm{Na}$ indústria da construção civil, quando se refere a flexibilidade estratégica, a integração parcial é similar a integração total, pois elas removem as restrições de nichos de mercados (VILLACRESES apud SERRA, 2001).

De uma maneira geral, a quase-integração vertical caracteriza-se por (LIPIETZ; LEBORGNE apud VILLACRESES, 1994): a) relações estáveis entre fornecedores e clientes; b) uma importante participação do cliente no volume de negócios do fornecedor; c) um campo de subcontratação intenso, indo da concepção à comercialização; d) formas não mercantis de relações interformas, indo da subordinação à parceria.

Dessa forma, "as relações de subcontratação que têm um caráter permanente, representam a essência da quaseintegração" (SALLEZ apud VILLACRESES, 1994).

Sallez (1962) faz uma analogia entre a subcontratação e a quase-integração no sentido de serem definidas a partir de dois critérios: a) um critério de "substituição", que pressupõe a transferência de responsabilidade do cliente para o subcontratado; b) um critério, mencionado na época por Sallez (1962) como "novo", de "ligação duradoura", que pressupõe uma colaboração e uma interdependência das duas partes, muito semelhante ao conceito atual de parceria (SALLEZ apud VILLACRESES, 1994).

A quase-integração vertical se mostra um tipo de relacionamento muito competitivo no mercado pelo fato das formas clássicas fordistas caminharem paralelamente a existência da firma especializada, dotada de capacidade de concepção e, correlatamente, o desenvolvimento de parceria no interior do relacionamento (VILLACRESES, 1994).

Finalmente, as estratégias não-integradas são utilizadas para a obtenção de materiais sem precisar recorrer a transferências internas nem aos riscos da propriedade, sendo, portanto, representadas pela contratação (VILLACRESES, 1994).

As empresas de construção devem fazer o menos possível dentro da empresa, comprando a maioria de seus produtos no mercado. Assim, fica claro o por que do modelo simplificado das estratégias de integração vertical sugerir que as empresas de construção devem procurar estratégias de quase-integração (fazendo uso da subcontratação) ou de não-integração por meio de contratação (VILLACRESES, 1994).

\section{SUBCONTRATAÇÃO VERSUS TERCEIRIZAÇÃO}

Tanto o termo subcontratação como terceirização apontam na mesma direção quando referem-se ao processo através do qual as empresas transferem para terceiros atividades anteriormente desenvolvidas por elas (BRANDLI, 2000).

Existem algumas discordâncias entre terceirização e subcontratação. Vários autores incorporam estes conceitos de acordo com os tipos de atividades envolvidas. Lieira,
Queiroz, Davis, Leite (apud BRANDLI, 2000 p. 32) informam que a terceirização refere-se à transferência das atividades-meio (atividades de apoio) que até então eram realizadas pelas próprias unidades de produção e/ ou serviços da empresa. No tangente a subcontratação, envolve a transferência das atividades-fins da empresa.

Paralelamente, existem autores que defendem que não há diferença entre subcontratação e terceirização no que concerne ao tipo de atividade envolvida. "Nos vários setores industriais esses termos são utilizados corriqueiramente como sinônimos por empresários e profissionais atuantes, sem preocupação relacionada ao seu conceito e origem" (SERRA, 2001, p. 88).

Parece importante atentar-se para o posicionamento de Silva (apud BRANDLI, 2000, p. 33), que encara a terceirização como uma nova forma de gestão organizacional e que sob a ótica da parceria, muitas vezes pode ser confundida com a subcontratação. Pagnani (apud BRANDLI, 2000, p. 33), deixa claro que a estratégia de subcontratação na pequena e média empresa pode ser fiel a todos os princípios da terceirização.

"Contudo, verifica-se a existência de uma divergência entre as várias definições dos autores pesquisados e a interpretação subjetiva da realidade do setor da construção por parte daqueles que tentam dar o veredicto final em assuntos jurídicos nessa área" (SERRA, 2001, p. 88).

$\mathrm{Na}$ indústria da construção civil, o emprego do termo subcontratação é considerado o mais adequado por Eccles (apud BRANDLI, 2000, p. 34), que defende a aplicação da definição terceirização um tanto ambígua nesta indústria, pelo fato da dificuldade em determinar a atividade-meio ou não-essencial de uma empresa de construção civil. Dessa forma, torna-se importante, para melhor desenvolvimento deste trabalho, considerar a subcontratação como repasse de atividades ligadas aos serviços de execução das obras.

\subsection{Razões para terceirizar}

Com base na própria estratégia e nas características do setor da construção, as empresas apontam várias razões para a subcontratação, apesar de identificarem grandes vantagens com relação à mão-de-obra própria (BRANDLI, 2000).

As principais razões para terceirizar se apresentam da seguinte forma (TOMÉ, 1998):

a) razões operacionais: minimização dos custos, relação custo $x$ benefício, pouca repetitividade do serviço e rapidez da execução.

b) razões táticas: redução do quadro de pessoal, redução de encargos sociais e redução de problemas com a legislação trabalhista, serviços específicos que necessitam de recursos.

c) razões estratégicas: eliminação de atividades secundárias da empresa e aumento da agilidade nas decisões. 


\subsection{Seleção dos parceiros}

Com base nos resultados apontados por Villacreses (1994), que tomou como estratégia de pesquisa a aplicação de uma escala de grau de importância variando de nenhuma importância (1) a importantíssimo (5), verifica-se os critérios de seleção para as empresas contratantes e subcontratantes. A pesquisa tratou de uma questão aberta que apontasse a percepção do subcontratante sobre a postura das empresas contratantes quanto ao processo de seleção. Os resultados obtidos junto às empresas contratantes estão apresentados no gráfico 1.

A partir da análise do gráfico 1, nota-se que o item mais relevante para os contratantes é a qualidade dos serviços. O fator cumprimento de prazos aparece como muito importante, ficando o preço como importante somente para três empresas.

Existe outra forma de selecionar os parceiros; os critérios de seleção e avaliação do prestador de serviço podem ser vistos também da seguinte forma (TOMÉ, 1998):

a) aspectos considerados pelo nível operacional: custo das empresas a serem contratadas para executar os serviços, relação custo $\mathrm{x}$ benefício e menor preço, através de licitação de acordo com a lei 8.666, quando a seleção é para empresas públicas;

b) o nível tático de decisão utiliza os fatores: qualidade dos produtos ou serviços prestados, informações com outras empresas, do mesmo ramo ou porte semelhante ao da contratante, ou seja, buscar referências com outras tomadoras de serviço de um determinado prestador, coleta de preços dos prestadores de serviço, análise crítica das empresas candidatas à terceirização, observando seu porte, suas instalações, e, seu processo produtivo, acompanhamento dos serviços quando executados em outras empresas e serviços prestados anteriormente, ou seja, experiência em executar a atividade;

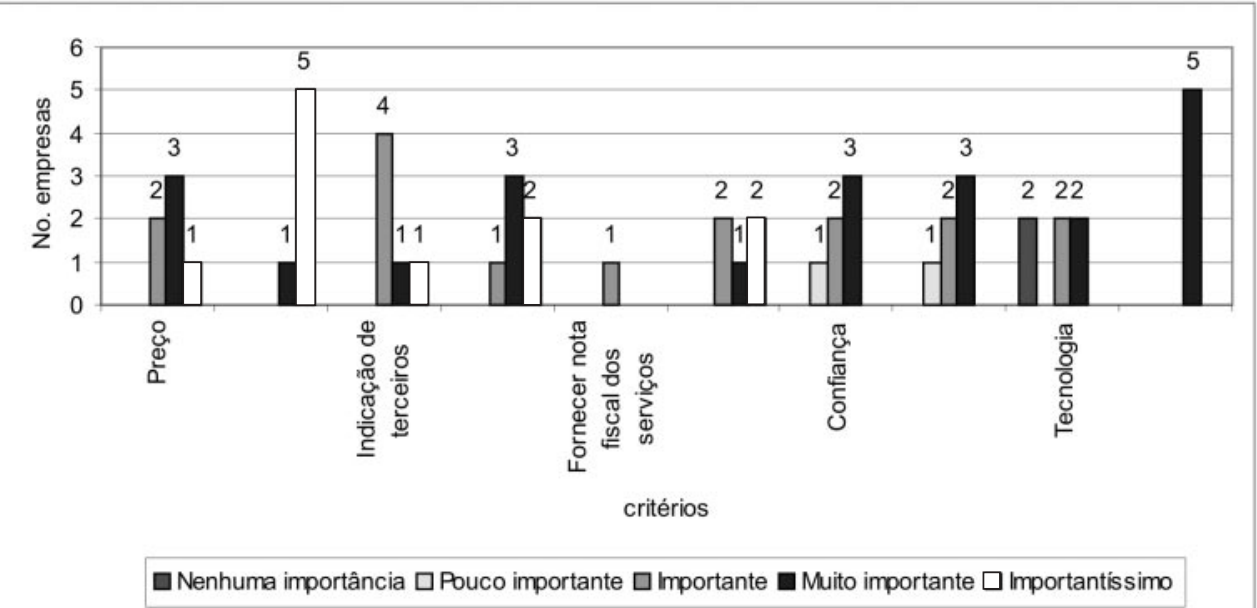

Gráfico 1 - Critérios de seleção de Subcontratantes (adaptado de Brandli, 1999) c) os fatores mais usadbs pelo nível estratégico são a idoneidade das empresas candidatas à prestação de serviço e empresas que se destacam na área.

\section{A NECESSIDADE DE PARCERIAS}

A necessidade de enxugar as estruturas organizacionais é uma das grandes tendências gerenciais atuais, ocasionando mudanças tecnológicas e organizacionais na produção de bens, ou, no setor de serviços (FALGETANO, 1995). Isto tem sido motivo para transformações ocorridas nas empresas dos mais diversos segmentos da economia. Estas transformações buscam otimizar a utilização de seus recursos e racionalizar os seus sistemas produtivos, recorrendo a processos de terceirização e de formação de parcerias com fornecedores, clientes e concor rentes (VALE, 1992). Segundo Villacreses (1994, p. 43):

[...] a indústria da construção deve procurar novas estratégias para diminuir custos e ganhar vantagem competitiva num ambiente em contínua mudança. A parceria é uma nova maneira de administrar um negócio neste novo ambiente. A competição global, o alto custo de desenvolvimento de produto e a crescente preocupação com a qualidade estão forçando os construtores a buscar métodos mais eficientes para executar suas obras. Os construtores e engenheiros estão procurando maneiras de crescer e de manter a competitividade [...].

Estrategicamente, o relacionamento contratantesubcontratante vai além do simples "fazer-ou-subcontratar", definindo a forma de posicionar a capacidade construtiva da empresa para maximizar os benefícios que possam resultar $\mathrm{da}$ combinação das habilidades internas da empresa com as forças de seus subcontratantes (LYONS et al. apud VILLACRESES, 1994). Conseqüentemente, percebe-se a importância das construtoras formarem uma parceria estratégica com as empresas contratadas.

A parceria pode ser entendida como um acordo de longo prazo entre duas ou mais organizações com o propósito de atingir objetivos específicos do negócio por meio da maximização da efetividade dos recursos de cada participante. Essa definição apresentada por Villacreses (1994), tendo como base o Construction Industry Institute, implica em mudar os relacionamentos tradicionais para uma cultura compartilhada sem considerar fronteiras organizacionais. 
Porter (1989) esclarece que ao buscar a competência essencial, uma determinada empresa emprega processos de terceirização ou de agregação de atividades. As forças que levam à tomada de decisões no sentido de aumentar ou diminuir o número de atividades totalmente controladas são definidas pela estrutura de custos operacionais, pelo potencial de controle estratégico e pelas metas de estratégias corporativas. Sendo assim, é necessário que as empresas busquem parcerias estratégicas para todas as atividades para as quais não estejam especializadas, no sentido de se agregar valor aos produtos e serviços.

A parceria oferece o potencial de responder rapidamente às oportunidades do mercado sem duplicação de recursos, pois enquanto a integração vertical administra o risco internalizando-o, a parceria distribui o risco entre várias entidades, reduzindo assim a exposição de cada participante (VILLACRESES, 1994). Portanto, o objetivo é mudar o posicionamento estratégico da empresa, tendo em vista que as metas da parceria estratégica são sustentar as capacidades críticas, incrementar o fluxo de inovação e melhorar a flexibilidade em resposta a mudanças tecnológicas e de mercado (CONRADS apud VILLACRESES, 1994).

As empresas encontram nas parcerias vantagens e oportunidades que dificilmente teriam num relacionamento tradicional. A junção dos pontos fortes contribui para o êxito do relacionamento.

Sendo assim, a necessidade de parcerias se confirma quando se analisa a evidência de todas as empresas terem que buscar a sua competência essencial através do aumento ou da redução do escopo de atividades totalmente controladas, através da terceirização, resultando em redução de custos e aumento da especialização. Contudo, a busca da competência essencial é feita através de alianças que permitem a manutenção de níveis ideais da qualidade de todos os processos na cadeia de valor (PORTER, 1989).

Tão importante quanto salientar a necessidade da parceria é lembrar das dificuldades para o seu estabelecimento. As barreiras que inibem o crescimento da parceria são: a) a cultura corporativa; b) os relacionamentos tradicionais proprietário-construtor-subcontratante / fornecedores e c) o tempo requerido para desenvolver a parceria. É necessário tempo e esforço significativo para encontrar o parceiro certo e para desenvolver um acordo de parceria eficaz (COOK; HANCHER apud VILLACRESES, 1994).

\section{METODOLOGIA}

Esta pesquisa orientada pelo enfoque qualitativo e exploratório foi baseada no método do estudo de caso, no qual foram escolhidas duas empresas que atuam no segmento de edificações residenciais da região de Fortaleza.

Segundo Triviños (apud BRANDLI, 2000), o estudo de caso descritivo permite conhecer com exatidão os fatos e fenômenos e aprofundar determinada realidade e a pesquisa qualitativa, que, por sua vez, caminha para o universo de significações, motivos, aspirações, atitudes, crenças e valores.

As empresas que compõem a pesquisa atuam no mesmo ramo do segmento imobiliário: construção de empreendimentos verticais para classe média alta, porém, são de portes diferentes: a empresa $\mathrm{X}$ é grande e a $\mathrm{Y}$ pequena.

A empresa $\mathrm{X}$ possui mais de 200 mil metros quadrados de área construídos, atuando no segmento de edificações residenciais, comerciais e obras públicas, estando atualmente com cinco obras em andamento no estado do Ceará. Além disso, a referida empresa possui certificação ISO 9001 e trabalha com obras sob o sistema de incorporação.

Especializada na construção de edificações residenciais e comerciais, a empresa $\mathrm{Y}$ possui mais de 50 mil metros quadrados de área construídos, possuindo cinco obras em andamento e certificação ISO 9001, além de trabalhar apenas em obras a preço de custo.

Como instrumento de coleta de dados foram realizadas entrevistas semi-estruturadas com altos gerentes das empresas do estudo de caso, pois estes são os responsáveis diretos pela decisão estratégica com relação à escolha de subcontratar ou não empresas para determinados serviços.

Cada entrevista teve a duração de aproximadamente 50 minutos e o roteiro da mesma encontra-se no apêndice 1. $\mathrm{O}$ mesmo foi adaptado do trabalho de Brandli (2000), visto que se encontraram semelhanças entre os objetivos pesquisados, sendo que o presente trabalho tem um objetivo mais focado no processo da escolha estratégica entre terceirizar ou não um serviço. Dessa maneira alguns questionamentos foram omitidos e outros inseridos no referido roteiro.

A análise dos dados foi realizada a partir da leitura cuidadosa do material proveniente das entrevistas e da percepção desenvolvida pelos pesquisadores ao longo do trabalho. A preocupação essencial na interpretação foi manter a fidelidade dos significados, bem como a busca de informações intrínsecas às declarações dos entrevistados.

Com isso, foram realizados comparativos entre as respostas obtidas por cada empresa, bem como comparações entre estas respostas de "mercado" com a literatura pesquisada. A partir dá foram tecidos comentários sobre o objetivo principal desta pesquisa que é o de analisar os critérios estratégicos que determinam a escolha de terceirizar ou não uma atividade.

\section{ANÁLISE DAS ENTREVISTAS}

$\mathrm{Na}$ empresa $\mathrm{X}$ as decisões sobre quais atividades serão terceirizadas ou subcontratadas depende de cada situação. Para pequenos serviços (baixo valor financeiro e curta duração) a decisão fica por conta da gerência regional. Se o valor for representativo e demandar um maior período de tempo, passa-se para a apreciação junto à diretoria. Para cada 
obra existe um planejamento, não sendo padrão a escolha sobre terceirizar ou não; se a empresa possuir recursos (mãode-obra) disponíveis no momento da decisão, opta por fazer o serviço em vez de terceirizar. Ou seja, uma equipe bem estruturada custa (financeiramente) menos do que contratar um terceirizado, segundo o respondente.

$\mathrm{Na}$ empresa $\mathrm{Y}$, as decisões sobre quais atividades serão terceirizadas ou subcontratadas são tomadas pela diretoria e gerência de planejamento e controle, existindo um padrão para esta escolha.

Verifica-se que as empresas analisadas possuem visões diferentes sobre a decisão de terceirizar, tendo a empresa $\mathrm{X}$ uma visão mais comercial enquanto a empresa $\mathrm{Y}$ uma visão mais estratégica.

Numa escala de importância variando de um a cinco (1 - menos importante / 5 - mais importante), as duas empresas caracterizaram qualidade como o item de maior importância, seguido do critério custo na hora de escolher as ativique o binômio qualidade-custo é considerado como critério fundamental na escolha das atividades a serem terceirizadas.

As atividades consideradas "chaves", tanto para a empresa X quanto para a empresa $\mathrm{Y}$ (orçamento, serviços de recursos humanos, planejamento e controle das obras), não são terceirizadas, seguindo o que a literatura trata (item 5).

No quadro 1 encontra-se um quadro com as principais atividades de uma obra consideradas no momento da terceirização e a decisão de cada empresa sobre estas atividades. dades a serem terceirizadas. Dessa forma, pode-se concluir

de médio porte, a existência de um quadro funcional reduzido dificulta a execução de diversas atividades.

Nas duas empresas, a partir da escolha das atividades a terceirizar, a seleção das empresas a ser subcontratadas se dá respeitando principalmente o aspecto qualidade.

Para as duas empresas, constata-se a existência de parceria a partir do momento em que a empresa subcontratada volta a executar o mesmo serviço em uma outra obra. Para que isso ocorra é necessário que, na obra anterior, a empresa tenha demonstrado níveis de qualidade e organização de acordo com o padrão estabelecido pela contratante. Entretanto devido à certificação de qualidade que as construtoras possuem, estas realizam sempre tomada de preços antes do início dos serviços, indo de encontro à filosofia de formação de parcerias (item 6).

As empresas apontaram como vantagem da terceirização o controle real e antecipado do custo do serviço, enquanto que com a mão-de-obra própria este custo pode variar. Com relação as desvantagens existe um custo com administração dos terceiros, além do risco que se corre com a perca de qualidade pelo mercado não ofertar certos serviços qualificados.

Outro problema apontado na subcontratação é a dificuldade que as empresas terceirizadas possuem para gerir sua mão-de-obra, acarretando uma preocupação a mais para a empresa contratante, com relação ao pagamento de direitos trabalhistas, por exemplo.

Como desvantagens da mão-de-obra própria consta-

\begin{tabular}{|l|c|c|}
\hline \multicolumn{1}{|c|}{ Atividade } & Empresa X & Empresa Y \\
\hline Serviço de fundações & Subcontrata & Subcontrata \\
\hline Execução da estrutura de concreto & Não subcontrata & Subcontrata \\
\hline Paredes e painéis (alvenaria) & Não subcontrata & Não subcontrata \\
\hline Serviços de instalações & Não subcontrata & Subcontrata \\
\hline Esquadrias de madeira & Não subcontrata & Subcontrata \\
\hline Esquadrias de alumínio & Subcontrata & Subcontrata \\
\hline Esquadrias de ferro & Subcontrata & Subcontrata \\
\hline Revestimento argamassado & Não subcontrata & Subcontrata \\
\hline Revestimento em gesso & Subcontrata & Subcontrata \\
\hline Forro de gesso & Subcontrata & Subcontrata \\
\hline Revestimento de fachada & Subcontrata & Subcontrata \\
\hline Assentamento de cerâmica/granito & Não subcontrata & Não subcontrata \\
\hline Impermeabilização & Subcontrata & Subcontrata \\
\hline Pintura (revestimento interno) & Subcontrata & Subcontrata \\
\hline
\end{tabular}

Quadro 1 - Relação de atividades subcontratadas

Esta diferença na quantidade de atividades terceirizadas entre as duas construtoras pode ser explicada pelo porte das empresas. No caso da empresa X, de grande porte, a existência de mão-de-obra qualificada própria é capaz de realizar uma grande quantidade de atividades. Já na empresa $\mathrm{Y}$, tou-se nas entrevistas que, se a equipe interna não estiver bem treinada, os níveis de qualidade estarão comprometidos. Entretanto, ao conseguir estabelecer um know-bow para a execução de determinados serviços, a construtora consegue uma vantagem com sua mãode-obra própria por aumentar a experiência desta.

\section{CONSIDERAÇÕES FINAIS}

Com a crescente competitividade no mercado, as empresas passaram a desenvolver formas alternativas de organização empresarial. $\mathrm{Na}$ indústria da construção civil a subcontratação passou a ser uma estratégia amplamente utilizada, apesar de responder mais como uma estratégia implícita de adaptações às condições de mercado do que uma estratégia competitiva. 
A essência deste trabalho foi considerar a subcontratação como elemento estratégico da empresa de construção. Porém, verificou-se a necessidade de abordar o planejamento estratégico da empresa com mais atenção, de uma maneira sistemática e estruturada. Dessa forma, o construtor passaria a tornar esta estratégia implícita numa estratégia competitiva explícita através do planejamento estratégico formal.

Por conseguinte, observa-se que a análise estratégica da integração vertical indica a conveniência de baixos níveis de integração em grade parte das empresas de construção. Apesar de um cenário marcado pela necessidade das empresas em aumentar a qualidade dos produtos/serviços, melhorar a produtividade da mão-de-obra e reduzir os custos, as vantagens e desvantagens da subcontratação dependem do contexto de cada organização.

A subcontratação na construção civil deve ser tratada com alguns diferenciais em relação aos demais setores do mercado, por apresentar características intrínsecas ao setor, como a rotatividade da mão-de-obra devido a sazonalidade $\mathrm{da}$ produção, entre outras.

O binômio qualidade-custo é o principal fator que motiva as empresas a decidir que atividades terceirizar. Posterior mente, a escolha do subcontratado depende principalmente da qualidade dos seus serviços, visto que o custo já foi analisado na etapa inicial.

Notou-se uma visão míope em relação a definição de parceria por parte dos entrevistados, isto por que parceria vai além de somente continuar executando os mesmos serviços com a mesma empresa.

Visualizou-se que a empresa $\mathrm{X}$ por ter um porte maior terceiriza menos atividades pois possui mais mão-de-obra disponível, isto gera uma menor experiência no assunto subcontratação, acarretando, conseqüentemente, em uma visão comercial do tópico.

Já a empresa Y, se trata de uma empresa menor que terceiriza mais seus serviços, obtendo maior experiência no assunto e uma conseqüente visão mais estratégica.

Diferenciando-se da literatura pesquisada, além do custo, o fator qualidade aparece nas respostas dos funcionários como premissa básica na decisão sobre terceirização dos serviços.

Devido aos diversos fatores apresentados neste estudo, verifica-se que a visão de mercado obtida através da pesquisa qualitativa realizada está semelhante ao levantamento bibliográfico realizado.

\section{REFERÊNCIAS BIBLIOGRÁFICAS}

BARROS NETO, José de Paula. Proposta de um modelo de formulação de estratégia de produção para pequenas empresas de construção babitacional. 1999.
Tese (Doutorado em Administração) - Programa de Pós-graduação em Administração, Universidade Federal do Rio Grande do Sul, Porto Alegre, 1999.

BRANDLI, Luciana L. A estratégia de subcontratasão e as relacōes organizacionais na construção civil de Florianópolis. (Coleção trabalhos acadêmico-científicos. Série dissertações de mestrado). Ijuí: Editora Unijuí, 2000.

FALGETANO, Edylita. Terceirização conquista seus aliados. Revista Administração, no. 6, janeiro 1995.

MELLO, Rodrigo B. O estudo da mudanç estratégica organizacional em pequenas empresas de construsão de edificacooes: um estudo de caso em Florianópolis. 1997. Dissertação (Mestrado em Engenharia de Produção) - Programa de Pós-graduação em Engenharia de Produção, Universidade Federal de Santa Catarina, Florianópolis, 1997.

PALACIOS, Victor Hugo R.; VILLACRESES, Xavier E.R. Análise do perfil estratégico de empresas de construção civil de pequeno porte. In: FORMOSO, Carlos Torres (ed). Gestão da qualidade na construção civil: uma abordagem para empresas de pequeno porte. Porto Alegre: Programa de Qualidade e Produtividade da Construção Givil no Rio Grande do Sul, 1994.

PORTER, Michael E. Estratégia Competitiva: Técnicas para Análise de Indístria e da Concorrência. Rio de Janeiro: Ed. Campus, 1986.

PORTER, Michael E. Como as forças competitivas moldam a estratégia. Harvard Business Review, maio-jun. 1989.

PORTER, Michael E. Vantagem Competitiva: criando e sustentando um desempenho superior. Rio de Janeiro: Campus, 1985.

PORTO, Clarice B. Redes de empresas: uma nova configuração organizacional para as micro, pequenas e médias empresas da indústria da construção civil - subsetor de edificações. 1999. Dissertação (Mestrado em Engenharia Civil) - Programa de Pós-Graduação em Engenharia Civil da Universidade Federal Fluminense, Niterói, 1999.

SERRA, Sheyla M. B. Diretrizes para gestão dos subempreteiros. 2001. 360 f. Tese (Doutorado em Engenharia da Construção Civil e Urbana) - Programa de Pós-Graduação em Engenharia da Construção Civil da Escola Politécnica da Universidade de São Paulo, São Paulo, 2001.

SOARES, Carlos Alberto P. Modelo de sistema de gestão aplicado a empresas de construção. Tese (Doutorado em Engenharia de Produção) - Programa de Pós-Graduação em Engenharia de Produção da COPPE UFRJ, Rio de Janeiro, 1997.

TOMÉ, Danusa M. Metodologia para estruturar o processo de terceiriząăão. Dissertação (Mestrado em Engenharia de Produção) - Programa de Pós-Graduação em Engenharia de Produção da Universidade Federal de Santa Catarina, Florianópolis, 1998.

VALE, Gláucia V. V. Terceirização e Competitividade. Rumos, p. 18-22, setembro/outubro 1992.

VILLACRESES, Xavier E. R. Análise estratégica da subcontratasãa em empresas de construção de pequeno porte. Dissertação (Mestrado em Engenharia de Construção) - Programa de Pós-Graduação da Escola de Engenharia da Universidade Federal do Rio Grande do Sul, Porto Alegre, 1994. 
